\title{
Acceleration of Carbon Fixation in Chilling-Sensitive Banana under Mild and Moderate Chilling Stresses
}

\author{
Jing Liu ${ }^{1}$, Tomáš Takáč ${ }^{2}{ }^{\circledR}$, Ganjun $\mathrm{Yi}^{3}{ }^{3}$, Houbin Chen ${ }^{1}$, Yingying Wang ${ }^{1}$, Jian Meng ${ }^{1}$, \\ Weina Yuan ${ }^{1}$, Yehuan Tan ${ }^{1}$, Tong Ning ${ }^{1}$, Zhenting He ${ }^{1}$, Jozef Šamaj ${ }^{2}$ and Chunxiang Xu ${ }^{1, *}$ \\ 1 Department of Pomology, College of Horticulture, South China Agricultural University, Guangzhou 510642, \\ China; 15800231068@163.com (J.L.); hbchen@scau.edu.cn (H.C.); wyy199008@163.com (Y.W.); \\ mengjian2019@163.com (J.M.); 17818521882@163.com (W.Y.); t13416479181@163.com (Y.T.); \\ nt8023@163.com (T.N.); 18734453308@163.com (Z.H.) \\ 2 Centre of the Region Haná for Biotechnological and Agricultural Research, Department of Cell Biology, \\ Faculty of Science, Palacký University, 78371 Olomouc, Czech Republic; tomas.takac@upol.cz (T.T.); \\ jozef.samaj@upol.cz (J.Š.) \\ 3 Guangdong Province Key Laboratory of Tropical and Subtropical Fruit Tree Research, Institute of Fruit Tree \\ Research, Guangdong Academy of Agricultural Sciences, Guangzhou 510640, China; yiganjun@vip.163.com \\ * Correspondence: chxxu@scau.edu.cn
}

Received: 31 October 2020; Accepted: 28 November 2020; Published: 7 December 2020

check for updates

\begin{abstract}
Banana is one of the most important food and fruit crops in the world and its growth is ceasing at $10-17^{\circ} \mathrm{C}$. However, the mechanisms determining the tolerance of banana to mild $\left(>15^{\circ} \mathrm{C}\right)$ and moderate chilling $\left(10-15^{\circ} \mathrm{C}\right)$ are elusive. Furthermore, the biochemical controls over the photosynthesis in tropical plant species at low temperatures above $10{ }^{\circ} \mathrm{C}$ is not well understood. The purpose of this research was to reveal the response of chilling-sensitive banana to mild $\left(16{ }^{\circ} \mathrm{C}\right)$ and moderate chilling stress $\left(10{ }^{\circ} \mathrm{C}\right)$ at the molecular (transcripts, proteins) and physiological levels. The results showed different transcriptome responses between mild and moderate chilling stresses, especially in pathways of plant hormone signal transduction, ABC transporters, ubiquinone, and other terpenoid-quinone biosynthesis. Interestingly, functions related to carbon fixation were assigned preferentially to upregulated genes/proteins, while photosynthesis and photosynthesis-antenna proteins were downregulated at $10{ }^{\circ} \mathrm{C}$, as revealed by both digital gene expression and proteomic analysis. These results were confirmed by qPCR and immunofluorescence labeling methods. Conclusion: Banana responded to the mild chilling stress dramatically at the molecular level. To compensate for the decreased photosynthesis efficiency caused by mild and moderate chilling stresses, banana accelerated its carbon fixation, mainly through upregulation of phosphoenolpyruvate carboxylases.
\end{abstract}

Keywords: banana (Musa spp. AAA); mild chilling; carbon fixation; photosynthesis; phosphoenolpyruvate carboxylases; immunofluorescence labeling

\section{Introduction}

Low temperature (LT) is one of the major environmental factors which not only limit the productivity and the geographical distribution of crops but also cause significant losses $[1,2]$. In recent years, modern high-throughput expression profiling techniques, such as genomics, transcriptomics, and proteomics, have provided useful tools for better understanding the roles of genes when responding to LT stresses [3-7]. However, most of these studies reported about the effects of severe LT $\left(\leq 10^{\circ} \mathrm{C}\right)$ on temperate [5,7-9], tropical, and subtropical [3,4,10] plants. Thus, information about the gene expression dynamics of tropical crops in response to mild $\left(>15^{\circ} \mathrm{C}\right)$ and moderate chilling $\left(10-15^{\circ} \mathrm{C}\right)$ is scarce [11,12], and the underlying molecular background is not well understood. 
Banana (Musa spp.) is a very important tropical crop with annual production of 153 million tons [13] and is very sensitive to LT [1]. Banana grows best when the temperature is between 24 and $32{ }^{\circ} \mathrm{C}$, while its growth ceases at $10-17^{\circ} \mathrm{C}$ [14], depending on the species and cultivars, developmental stage, and the length of exposure to LT [15]. The critical LT for the growth of most cultivated banana cultivars in China is approximately $13^{\circ} \mathrm{C}$ [16]. Chilling temperatures that range between 10 and $15.5^{\circ} \mathrm{C}$ frequently appeared in winter and early spring in tropical and subtropical banana production regions and seriously threaten the productivity of banana [17]. Therefore, it is very necessary to understand the molecular mechanism of banana tolerance to mild to moderate chilling.

High-throughput techniques have also been employed to reveal the mechanism of banana tolerance to LT stresses. A proteomic analysis was carried out with a chilling-tolerant (CT) cultivar (Musa spp. ABB) after exposure to $8{ }^{\circ} \mathrm{C}[10]$ and a chilling-sensitive (CS) one treated at $5^{\circ} \mathrm{C}$ [18]. A total of 809 differentially expressed genes (DEGs) showed differential expression in the CT banana cultivar, and many of these genes were involved in oxidation-reduction reactions, photosynthesis, and photorespiration [10]. However, only 41 protein spots exhibited a change in intensity by at least 2-fold in the CS one, including several proteins related to photosynthesis [18]. Yang et al. [3] compared different molecular responses of a CS Musa spp. AAA and CT Musa spp. ABB to LT of $10^{\circ} \mathrm{C}$ (LT10) using RNA sequencing (RNA-Seq). The involved pathway related to the 17 DEGs uniquely present in the CT cultivar included abiotic stress, signal transduction, photosynthesis, and photorespiration, and so on. Recently, changes in mRNA and long noncoding RNAs (lncRNAs) of a CT wild banana (Musa itinerans) with growth ceasing temperature at $0{ }^{\circ} \mathrm{C}$ [19] in response to different LTs $(13,4$, and $0{ }^{\circ} \mathrm{C}$ ) were analyzed, and photosynthesis, photosynthetic-antenna proteins, circadian rhythm, starch and sucrose metabolism, and cutin and suberine biosynthesis were found to be altered by these cold stress conditions [20]. Thus far, to our knowledge, there is no study focused on the molecular responses of the CS banana cultivar to $\mathrm{LT}$ above $10^{\circ} \mathrm{C}$, a stress frequently encountered by banana and other tropical crops.

Photosynthesis is one of the most temperature-sensitive processes in plants. To be adapted to the fluctuation in temperature, most plants could adjust their photosynthetic characteristics considerably [21]. Limited information exists about the photosynthesis acclimation strategies of banana during mild LT stress.

Therefore, here we aimed to reveal the whole-transcriptome gene expression patterns of the CS banana cultivar "Baxijiao" (Musa AAA, with annual production of several million tons) to moderate LT10 and mild LT of $16^{\circ} \mathrm{C}$ (LT16). We complemented this transcriptome with proteome changes in response to LT10. By this approach, we identified the transcriptional and protein landscape associated with its response of banana to mild to moderate chilling. In addition, we focused on the photosynthesis responses of this banana cultivar to LT stresses at the molecular (transcripts, proteins) and physiological levels. The results suggest that CS banana responded to LT16 more strongly at the molecular level when compared to LT10, and there were considerable differences in gene expression profiles between LT16 and LT10. Most importantly, our data revealed that the expression and abundance of genes/proteins related to carbon fixation and the majority of key photosynthetic enzymes increased significantly in CS banana after exposure to LT10 and/or LT16.

\section{Results}

\subsection{Morphological and Physiological Changes of Banana in Response to Mild and Moderate Chilling Stress}

The banana seedlings started to show light wilting due to water deprivation at $16^{\circ} \mathrm{C}$ after 2 days, as shown in Figure 1a,b. Hydrophanous spots could be observed on the youngest fully developed leaf 2 days after the temperature drop to $10^{\circ} \mathrm{C}$, as shown in Figure 1c. The relative electrolyte leakage of the control $\left(\mathrm{CK}\right.$, at $25{ }^{\circ} \mathrm{C}$ ) banana plants was $22.53 \%$. It significantly increased to $26.15 \%$ when the temperature dropped to $16{ }^{\circ} \mathrm{C}$ and further increased to $28.00 \%$ at $10{ }^{\circ} \mathrm{C}$, but there was no significant difference between LT10 and LT16. Similarly, the leaf damage rate also continuously increased with 
the temperature drop, as shown in Figure 1d. These data show that both LT16 and LT10 had damaging effects on membranes in banana. The Rubisco activity of banana increased after exposure to LT, though not at significant level, as shown in Figure 1e, pointing to the preservation of carboxylation processes in the CS banana cultivar. This is consistent with the stabile intercellular $\mathrm{CO}_{2}$ concentration under both treatments, as shown in Figure 1f. In addition, the phosphoenolpyruvate carboxylase (PEPC) activity significantly increased from $0.64 \mu \mathrm{mol} \mathrm{g}^{-1} \mathrm{~min}^{-1}$ (CK) to $1.27 \mu \mathrm{mol} \mathrm{g}^{-1} \mathrm{~min}^{-1}$ at LT10, though there was a slight decrease when the temperature dropped from $25^{\circ} \mathrm{C}$ to $16^{\circ} \mathrm{C}$, as shown in Figure $1 \mathrm{~g}$. The stomatal conductance was substantially affected by both temperatures and it decreased significantly from $251.8 \mathrm{mmol} \mathrm{m}^{-2} \mathrm{~s}^{-1}$ at $25^{\circ} \mathrm{C}$ to approximately $85 \mathrm{mmol} \mathrm{m}^{-2} \mathrm{~s}^{-1}$ after the exposure to LT, as shown in Figure $1 \mathrm{~h}$. A slight decline was observed with both the soil plant analysis development (SPAD) value (indicating the relative content of chlorophyll), as shown in Figure 1i, and the net photosynthetic rate in LT treated banana plants, as shown in Figure $1 \mathrm{j}$. Differently, the quantum efficiency of photosystem II $(\mathrm{Fv} / \mathrm{Fm})$ in banana decreased significantly from 0.75 to 0.51 when the temperature dropped to $10{ }^{\circ} \mathrm{C}$, as shown in Figure $1 \mathrm{k}$, but it was unaffected at $16^{\circ} \mathrm{C}$.

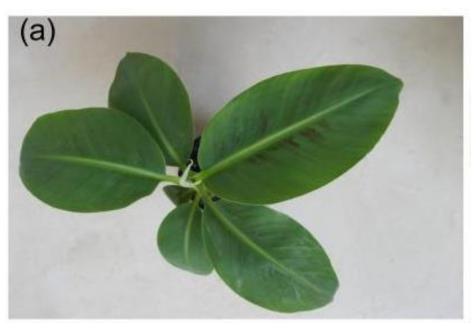

(d) Relative electrical conductivity

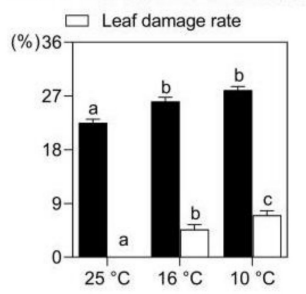

(h)

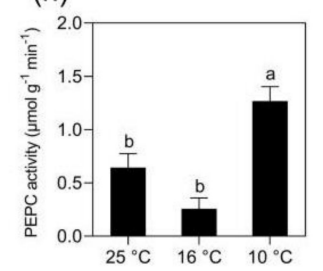

(e)

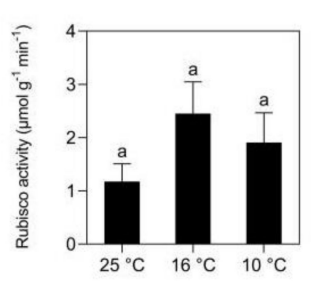

(i)

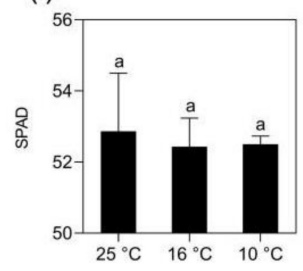

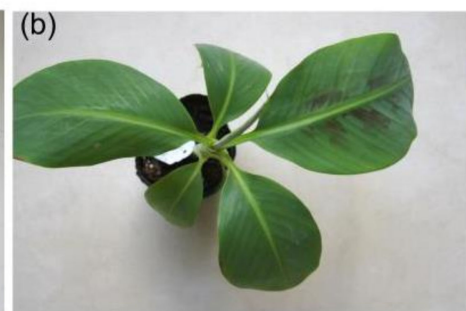

$\frac{-1}{\bar{c}}(\mathrm{f})$

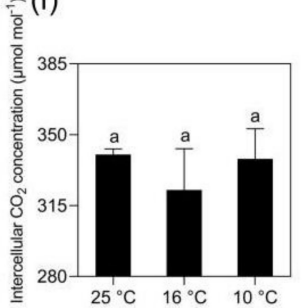

(j)

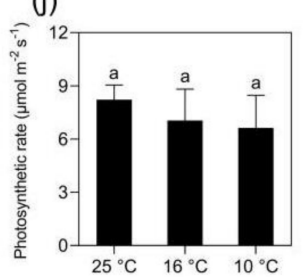

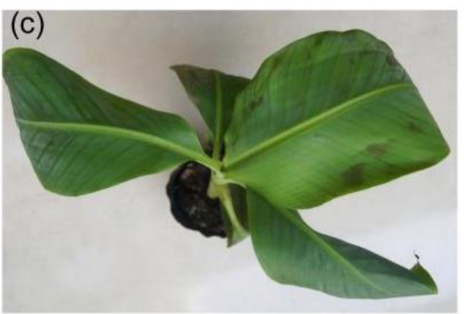

(g)

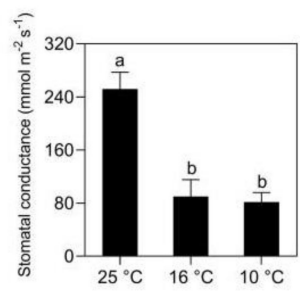

(k)

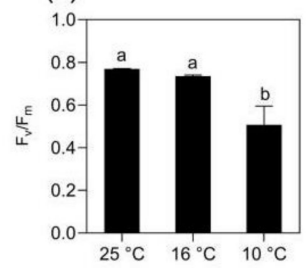

Figure 1. The symptoms and changes in physiological parameters of Musa spp. AAA cv. Baxijiao upon chilling stress. (a-c) Banana plants incubated at $25^{\circ} \mathrm{C}, 16^{\circ} \mathrm{C}$ or $10^{\circ} \mathrm{C}$ for 2 days; (d-k) Determination of the physiological parameters in the Musa spp. AAA cv. Baxijiao at $25^{\circ} \mathrm{C}, 16^{\circ} \mathrm{C}$, and $10^{\circ} \mathrm{C}$. Data represent an average of three replicates \pm standard error. Different letters above the columns represent significant difference using Duncan's multiple range test at $p<0.05$ after angular transformation of the data.

\subsection{Transcriptomic Analysis of Banana Exposed to the Mild and Moderate Chilling Stress}

The RNA-Seq (digital gene expression, DGE) technique was employed to reveal the responses of a CS banana cultivar to mild and moderate chilling at transcript level. In total, six cDNA libraries were constructed consisting of two biological replicates each of CK, plants exposed to LT16 and to LT10, and subjected to sequencing on an Illumina HiSeq 2000 platform.

For easier analysis of results, DEGs, and the Kyoto Encyclopedia of Genes and Genomes (KEGG) among LT16 and CK, LT10 and CK, and LT10 and LT16 were designated as LT16-CK, LT10-CK, and LT10-LT16 in the present study. $\mid \log 2$ (fold change) $\mid>1$ and a false discovery rate (FDR) $<0.05$ were used as the threshold to evaluate the significance of DEGs. 


\subsubsection{Transcriptomic Analysis of Banana Exposed to $16^{\circ} \mathrm{C}$ Chilling Stress}

Treatment of banana with LT16 lead to the identification of 1933 DEGs, out of which 978 were upregulated and 955 were downregulated, as shown in Supplementary Table S1. All DEGs induced by LT16 were classified into 105 KEGG pathways, while the upregulated and downregulated genes were annotated by 82 and 85 annotations, respectively, as shown in Supplementary Table S2. The top 20 KEGG pathways (with the smallest FDR values) related to upregulated genes are shown in Supplementary Figure S1a. These mainly included carbon fixation, flavonoid biosynthesis, circadian rhythm, carbon metabolism, and cutin, suberine, and wax biosynthesis. Annotations related to circadian rhythm, plant-pathogen interaction, starch and sucrose metabolism, galactose metabolism, tropane, piperidine, and pyridine alkaloid biosynthesis ranked within the first five ones for the downregulated DEGs, as shown in Supplementary Figure S1b.

\subsubsection{Transcriptomic Analysis of Banana Exposed to $10^{\circ} \mathrm{C}$ Chilling Stress}

In total, LT10 induced differential expression of 1267 DEGs, comprising 724 upregulated and 543 downregulated DEGs, as shown in Supplementary Table S3.

DEGs induced by LT10 were classified into 103 KEGG pathways, including 89 and 72 pathways connected with up- or downregulated genes, respectively, as shown in Supplementary Table S4. The top 20 KEGG pathways related to upregulated genes are shown in Supplementary Figure S2a. The first five pathways (according to the corrected $p$ value) were glycolysis/gluconeogenesis, biosynthesis of secondary metabolites, carbon fixation, carbon metabolism, and biosynthesis of amino acids. Downregulated genes were mainly assigned to galactose metabolism, photosynthesis, photosynthesis-antenna proteins, starch and sucrose metabolism, and cyanoamino acid metabolism, as shown in Supplementary Figure S2b.

\subsubsection{Comparison of LT10 and LT16}

The comparison of transcriptomic data obtained at LT10 and LT16 provided 279 DEGs, while 175 of them were upregulated and 104 were downregulated, as shown in Supplementary Table S5.

DEGs of the LT10-LT16 comparison were classified into 36 KEGG pathways, as shown in Supplementary Table S6, including 24 and 18 pathways connected with up- or downregulated genes, respectively. The top 20 KEGG pathways related to upregulated genes included plant-pathogen interaction, glutathione metabolism, arachidonic acid metabolism, selenocompound metabolism, and starch and sucrose metabolism, as shown in Supplementary Figure S3a. KEGG pathways related to downregulated genes are assigned to plant hormone signal transduction, $A B C$ transporters, ubiquinone and other terpenoid-quinone biosynthesis, as well as starch and sucrose metabolism, and cutin, suberine, and wax biosynthesis, as shown in Supplementary Figure S3b.

\subsubsection{Evaluation of KEGG Pathways Enrichment}

In total, when taking the corrected $p$ value $\leq 0.05$ as the threshold, 12 KEGG pathways showed significantly differentially expressed enrichment. KEGG pathways analysis resulted in five significantly enriched items (carbon fixation in photosynthetic organisms, flavonoid biosynthesis, circadian rhythm-plant, plant-pathogen interaction, starch and sucrose metabolism) for DEGs found in response to LT16. Another four KEGG pathways (glycolysis/gluconeogenesis, biosynthesis of secondary metabolites, carbon metabolism, and galactose metabolism) significantly enriched after LT10 except carbon fixation in photosynthetic organisms, which were also present in LT16. There were three significantly differentially expressed KEGG pathways between these two LT treatments, namely plant hormone signal transduction, $\mathrm{ABC}$ transporters, and ubiquinone and other terpenoid-quinone biosynthesis, as shown in Figure 2. 


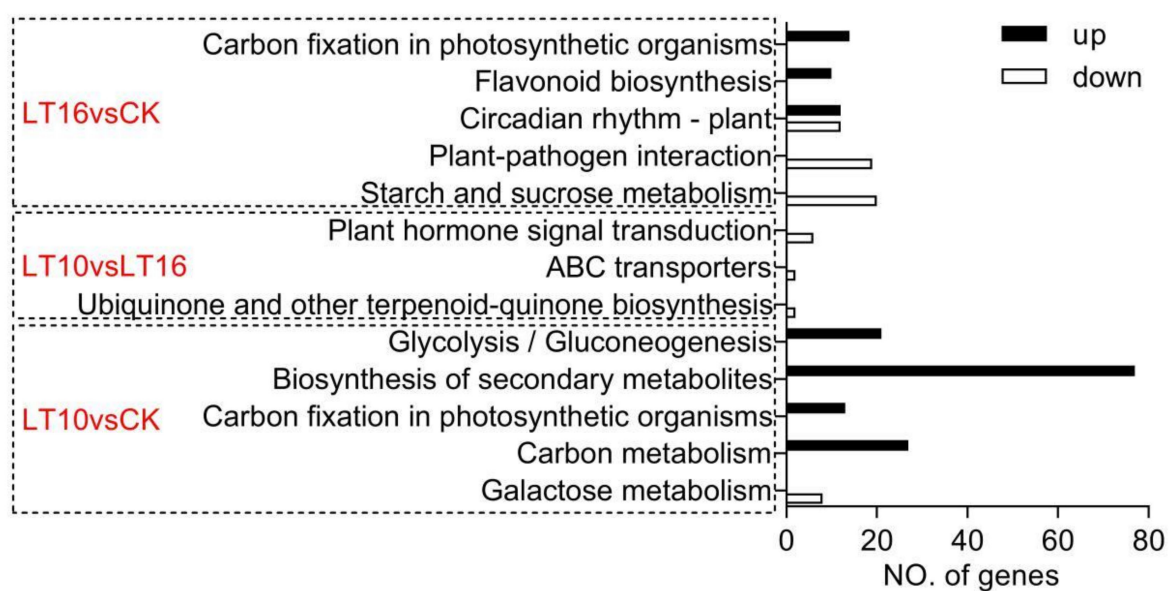

Figure 2. Kyoto Encyclopedia of Genes and Genomes (KEGG) pathways representation for banana (Musa spp. AAA cv. Baxijiao) upon mild and moderate chilling stress (corrected $p \leq 0.05$ ). The x-axis indicates the number of a specific category of genes in the main term. The y-axis shows the names of functional categories. CK; the control, LT10; low temperature (LT) of $10{ }^{\circ} \mathrm{C}$, LT16; LT of $16{ }^{\circ} \mathrm{C}$.

\subsection{Proteomic Analysis of Banana Exposed to Mild Chilling Stress}

For better understanding of banana response to moderate chilling at the protein level, the changes of proteome of CS banana cultivar leaves treated by $10{ }^{\circ} \mathrm{C}$ were analyzed by LC-MSMS combined with tandem mass tag quantification. In total, 110,693 out of 429,482 mass spectrum graphs and 5744 proteins were identified in the present study. Analysis revealed 366 differentially abundant proteins after LT10 treatment, out of which 196 proteins exhibited increased and 170 decreased abundance, as shown in Supplementary Table S7.

Data were evaluated by KEGG pathway analysis. These proteins could be assigned to 76 KEGG pathways, including the 10 most enriched ones with an FDR value $<0.0005$. These included carbon fixation in photosynthetic organisms, photosynthesis-antenna proteins, photosynthesis, porphyrin and chlorophyll metabolism, carbon metabolism, as well as metabolic pathways and biosynthesis of secondary metabolites, as shown in Figure 3.

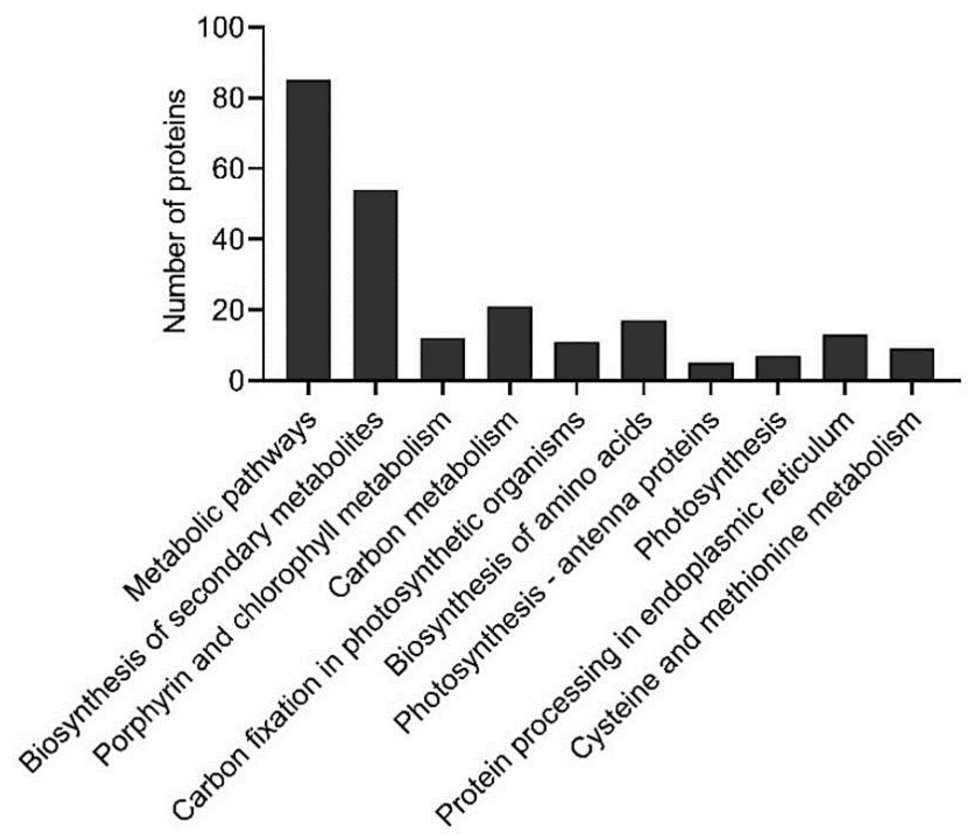

Figure 3. The most enriched KEGG pathways (corrected $p$ value $<0.0005$ ) related to differentially abundant proteins in banana (Musa spp. AAA) after exposure to $10^{\circ} \mathrm{C}$. 


\subsection{DEGs and Proteins Involved in Photosynthesis upon LT Stress}

\subsubsection{DGE Analysis}

Photosynthesis is one of the most LT-sensitive processes in plants. As mentioned above, carbon fixation in photosynthetic organisms was the only KEGG pathway significantly enriched commonly at both LT16 and LT10. Thus, we constructed a heat map for 26 and 19 DEGs related to carbon fixation and photosynthesis (FDR < 0.05), respectively, as shown in Figure 4 . This showed that except for two genes (pyruvate, phosphate dikinase, chloroplastic; and ribulose bisphosphate carboxylase small chain, chloroplastic), the other 24 DEGs related to carbon fixation showed relatively higher expression levels at LT16 and LT10 than at $25^{\circ} \mathrm{C}$, as shown in Figure $4 \mathrm{a}$. On the other hand, 11 (3 gene encoding proteins of PSI, 4 gene encoding proteins of PSII, and 4 genes assigned to KEGG pathway antenna proteins) out of 19 DEGs involved in light reactions of photosynthesis were downregulated in response to both LT16 and LT10, as shown in Figure 4b. On the other hand, six (chlorophyll $\mathrm{a}-\mathrm{b}$ binding protein $\mathrm{CP} 26$, chlorophyll $\mathrm{a}-\mathrm{b}$ binding protein 21 , ferredoxin-2, ferredoxin-NADP reductase, cytochrome b6-f complex iron-sulfur subunit, and the ATP synthase F1-dtta subunit family) of them were upregulated by LT16. However, their expression levels decreased at $10{ }^{\circ} \mathrm{C}$ but remained higher than at $25^{\circ} \mathrm{C}$. Only one gene (photosystem II 22 kilodalton (kDa) protein, chloroplastic) was upregulated at both LT16 and LT10 when compared to the control. The MapMan about DEGs involved in photosynthesis at LT16 and LT10 are shown in Supplementary Figures S5 and S6, respectively. The gene list identified in the present study is provided in the Supplementary data, as shown in Supplementary Table S8.

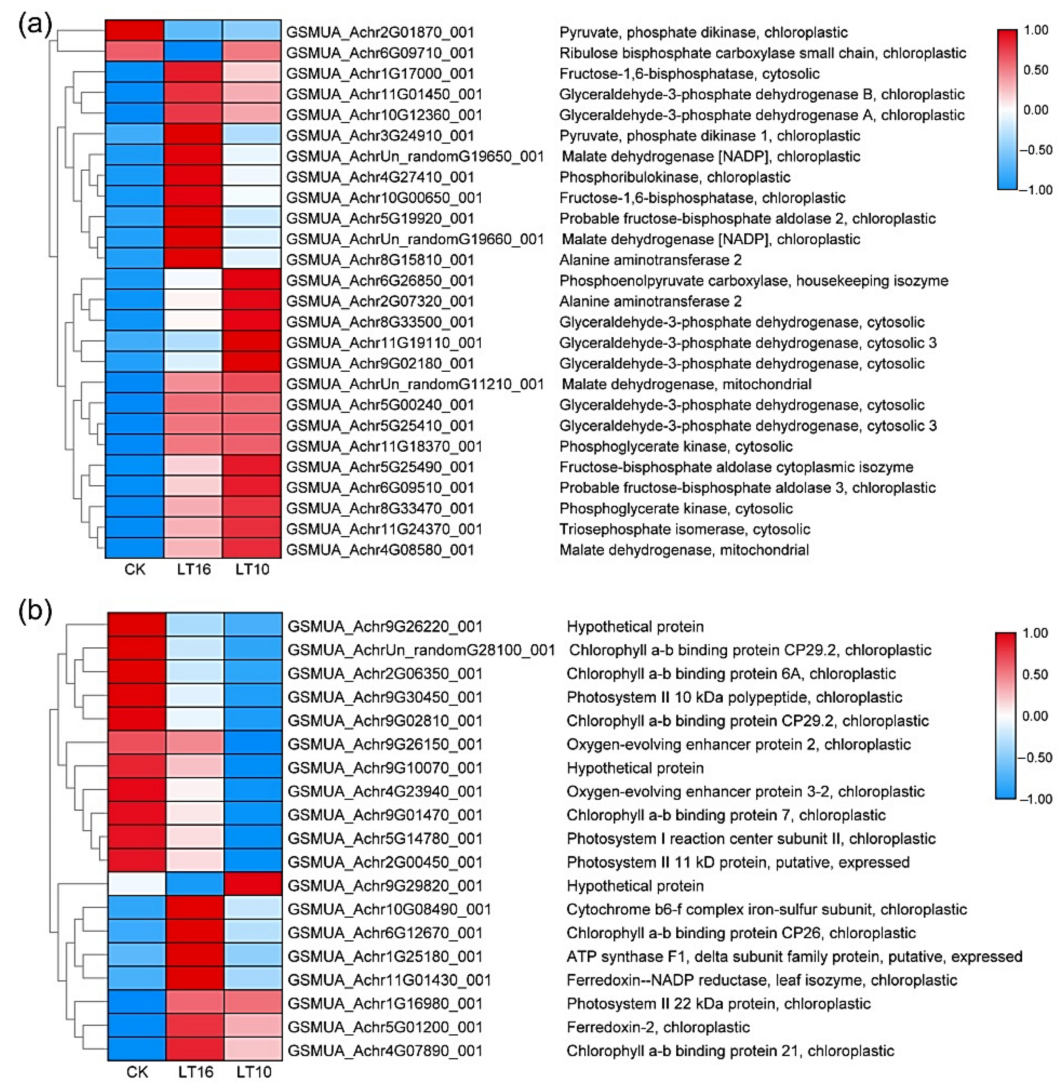

Figure 4. Heatmap showing the changes in expression (expected number of fragments per kilobase of transcript sequence per millions base pairs sequenced) of photosynthesis related genes in banana (Musa spp. AAA) in response to chilling stress. (a) DEGs related to carbon fixation; (b) DEGs related to photosynthesis and photosynthesis-antenna proteins. CK the control, $\mathrm{LT} 10 \mathrm{LT}$ of $10^{\circ} \mathrm{C}, \mathrm{LT} 16 \mathrm{LT}$ of $16^{\circ} \mathrm{C}$. 


\subsubsection{Proteomics Analysis}

The proteomic analysis showed that 12 proteins involved in PSI, PSII, and light-harvesting chlorophyll II protein complex/photosynthesis (antenna proteins) were downregulated. In contrast, 10 proteins related to carbon fixation in photosynthetic organisms were upregulated under LT, as shown in Figures 5 and 6. A complete list of differentially regulated proteins including details of their quantification is provided in the supporting information, as shown in Supplementary Table S8.

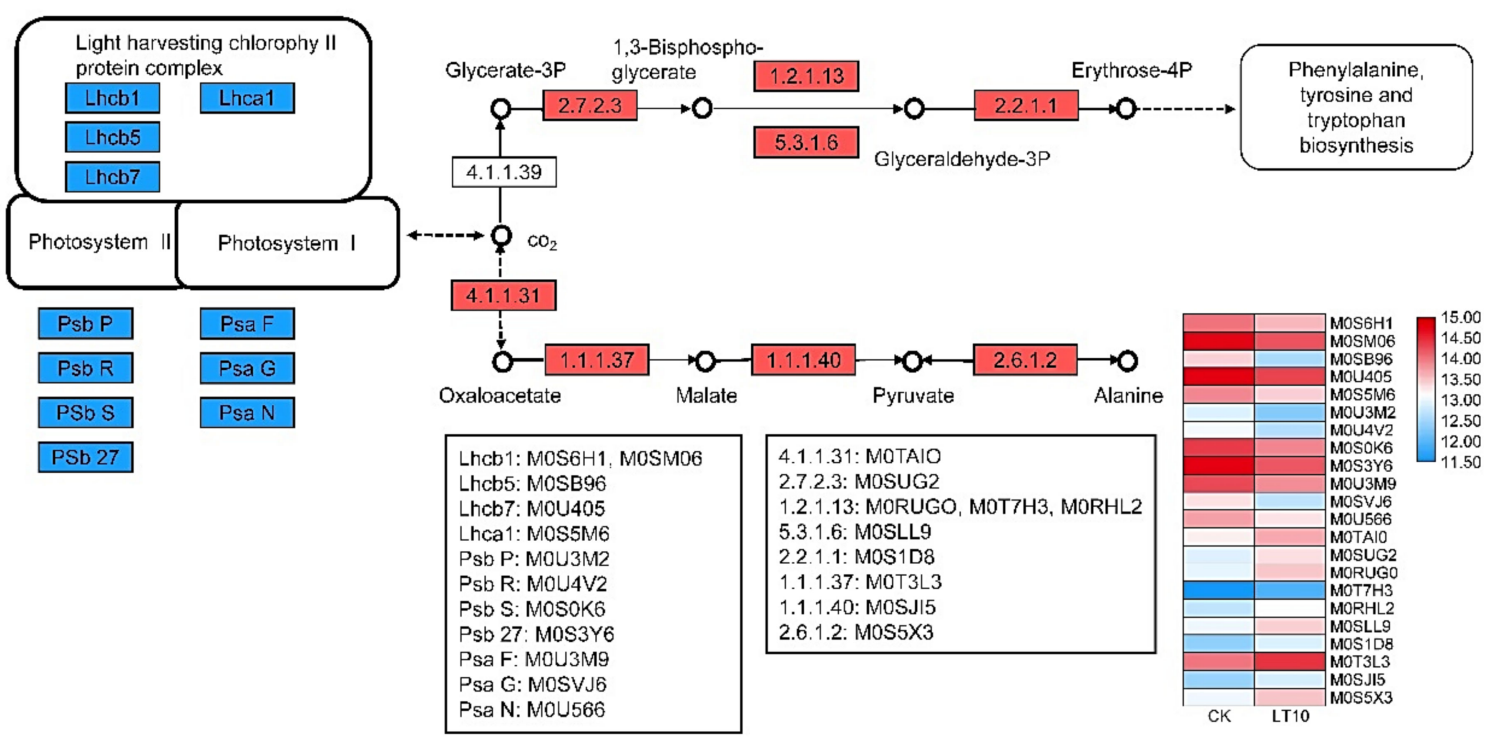

Figure 5. Diagram showing the abundance trends of photosynthesis-related proteins in banana (Musa spp. AAA) in response to $10{ }^{\circ} \mathrm{C}$.
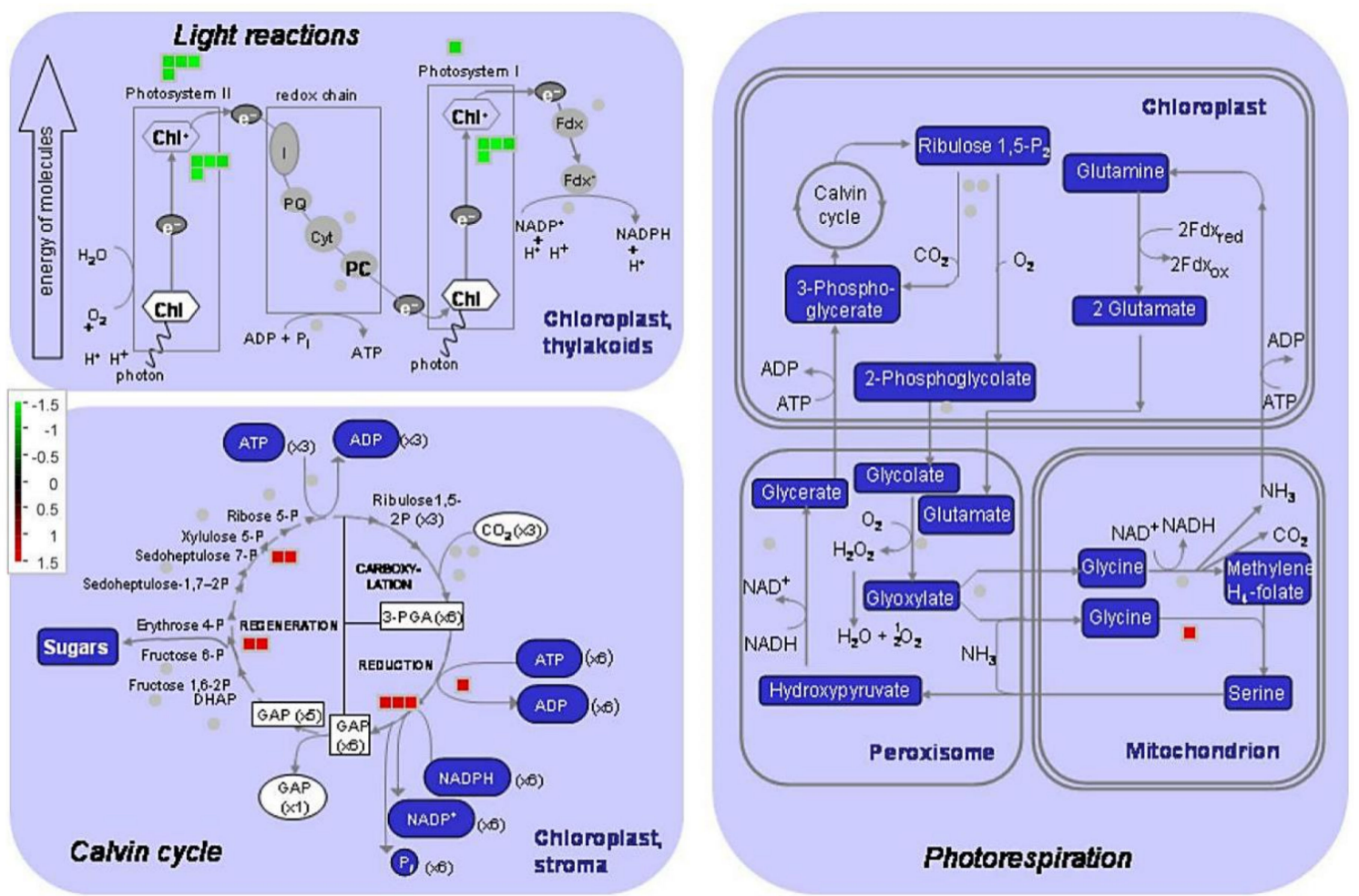

Figure 6. Diagram showing the changes in abundance of photosynthesis-related proteins in banana (Musa spp. AAA) in response to a low temperature of $10{ }^{\circ} \mathrm{C}$. 
As mentioned above, proteins and genes related to carbon fixation were upregulated in banana leaves in response to mild and moderate LT stress. Eight proteins/genes showed the same trends in both proteomics and RNA-Seq analyses. Among these, phosphoenolpyruvate carboxylase-housekeeping isozyme, glyceraldehyde-3-phosphate dehydrogenase A, and alanine aminotransferase 2 were upregulated at both the transcript and protein levels, while chlorophyll a-b binding protein $6 \mathrm{~A}$, oxygen-evolving enhancer protein 2, photosystem II $10 \mathrm{kDa}$ polypeptide, photosystem II $11 \mathrm{kDa}$ protein, and a hypothetical protein were downregulated. Another six proteins also showed consistent trends with their corresponding genes upon LT stress, although their changes at the transcript level were not significant due to the q value (the expected number of fragments per kilobase of transcript sequence per million base pairs sequenced; value difference was as high as or greater than 2 times). Among these six genes/proteins, three (photosystem I reaction center subunit $\mathrm{N}$, chlorophyll a-b binding protein $\mathrm{CP} 26$, and putative chlorophyll a-b binding protein type 1 member $\mathrm{F} 3$ ) were downregulated while the other three (lactate/malate dehydrogenase, glyceraldehyde-3-phosphate dehydrogenase B, and phosphoglycerate kinase) were upregulated.

\subsection{Validation of Transcriptomic Data Using $q P C R$ Analysis}

PEPC, Rubisco and pyruvate, phosphate dikinase (PPDK) are the key enzymes responsible for the photosynthesis of monocotyledons. Interestingly, nearly all members of these three families responded to LT significantly except three ones (MarbcS1, MaRca1, MaPEPC6), suggesting the importance of these three gene families in banana under mild and moderate LT stress. To validate these changes, the expression levels of all 20 genes belonging to these gene families before and after LT treatments were analyzed by qPCR. Among the six members of the PEPC family, the expression of MaPEPC2 increased significantly and the other four isoforms also showed insignificant increase in expression in response to LT; MaPEPC6 showed reduced levels, as shown in Figure 7a-f. Rubisco activase MaRca2 showed significant upregulation after LT10 but not LT16, as shown in Figure 7g-o. On the other hand, gene encoding of a small subunit of Rubisco, MarbcS4, was downregulated significantly by both LT16 and LT10. Though no significant differences were observed with the expression levels of the other seven Rubisco subunit isoforms in LT-treated banana, two of them are showing a slight increase while another four are regulated oppositely, as shown in Figure 7g-o. Similarly, two PPDK members showed a slight increase in expression, while another two isoforms were reduced, as shown in Figure $7 \mathrm{p}-\mathrm{t}$. In addition, we also validated the expression of randomly selected 21 DEGs involved in photosynthesis. The changes in their expression levels were consistent with those obtained from DGE analysis. Eight of the twelve genes assigned to carbon fixation pathway (MaMDH2, MaMDH3, MaGAPCp1, MaGAPA1, MaGAPB1, MaNADP-ME1, MaNADP-ME2, MaNADP-ME3) were upregulated, as shown in Figure 8a-1. Meanwhile, nine genes associated to photosynthesis and photosynthesis antenna were downregulated by LT, as shown in Figure $8 \mathrm{~m}-\mathrm{u}$. 


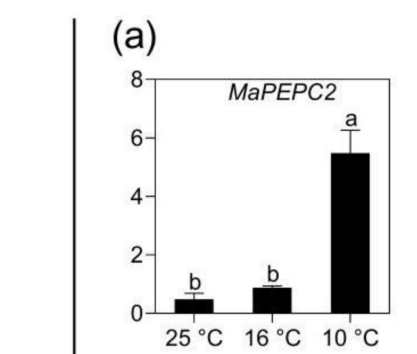

(e)

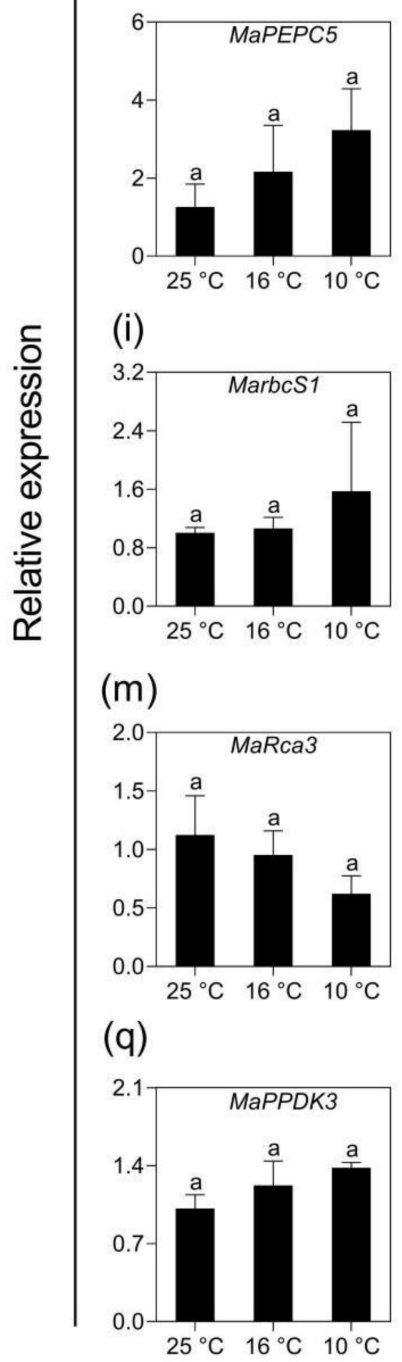

(b)

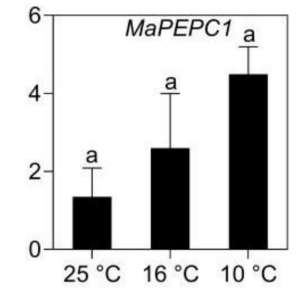

(f)

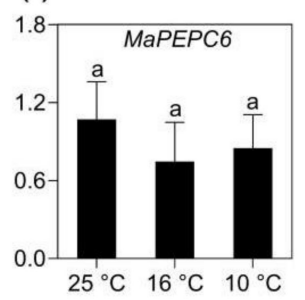

(j)

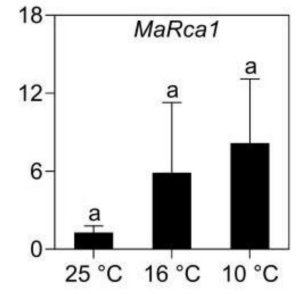

(n)

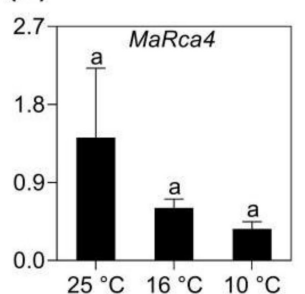

(r)

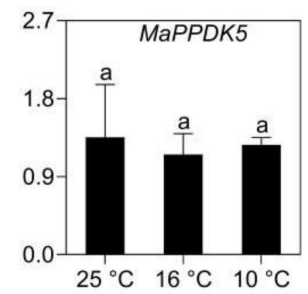

(c)

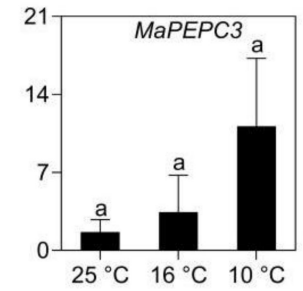

(g)

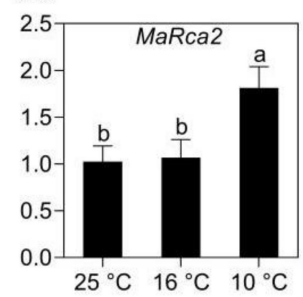

(k)

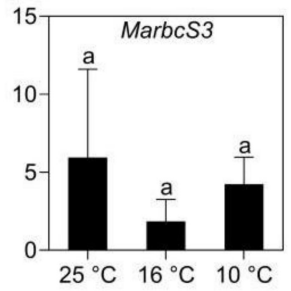

(0)

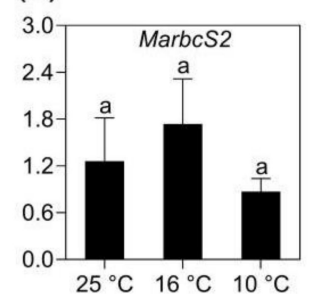

(s)

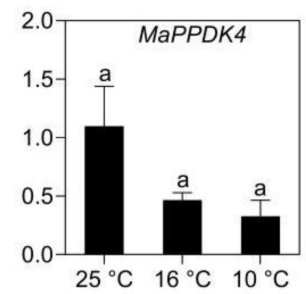

(d)

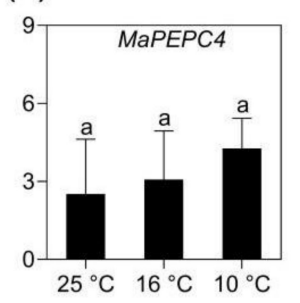

(h)

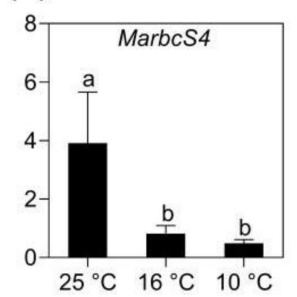

(I)

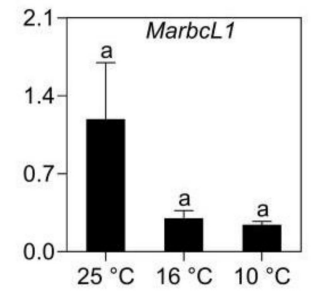

(p)

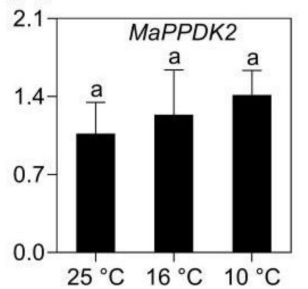

(t)

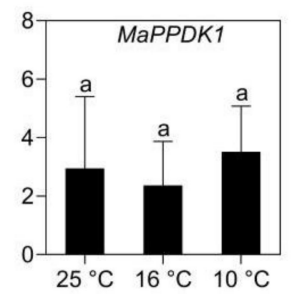

Figure 7. qPCR analysis of the expression of PEPC, Rubisco, and PPDK gene families in banana (Musa spp. AAA) exposed to low temperatures. (a-f) Phosphoenolpyruvate carboxylase (PEPC) genes; $(\mathbf{g}-\mathbf{o})$ Rubisco genes; $(\mathbf{p}-\mathbf{t})$ Pyruvate, phosphate dikinase (PPDK) genes. Data are the average of three replicates \pm standard error. Different letters above the columns represent significant difference using Duncan's multiple range test at $p<0.05$ after angular transformation of the data. 


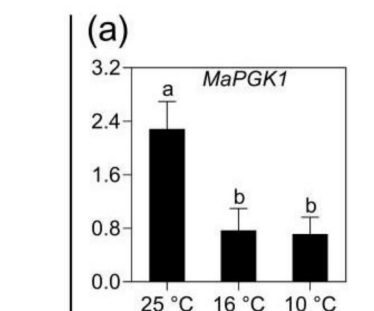

(b)

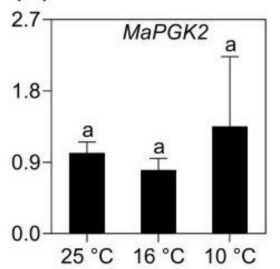

(d)

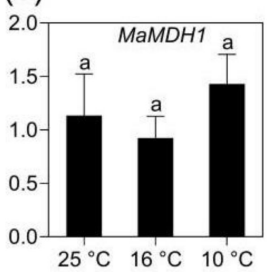

(g)

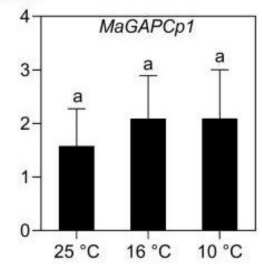

(j)

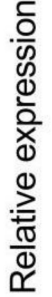

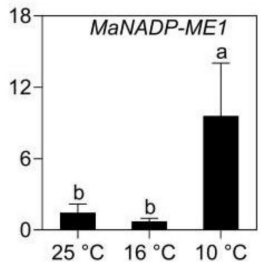

(m)

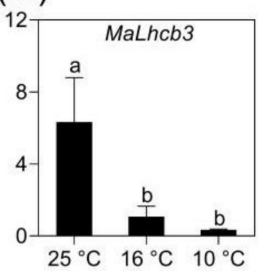

(p)

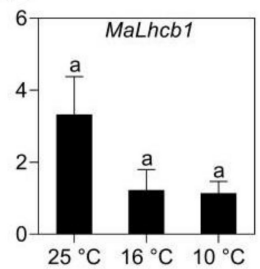

(s)

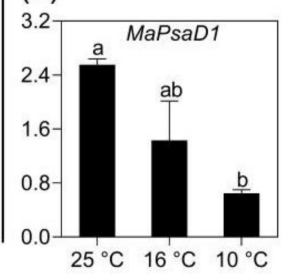

(e)

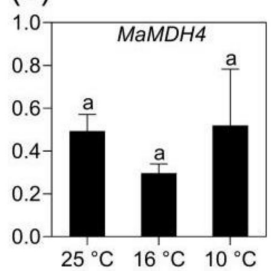

(h)

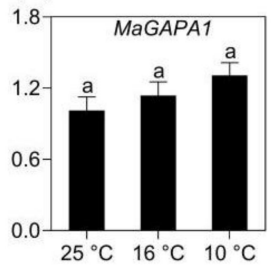

(k)

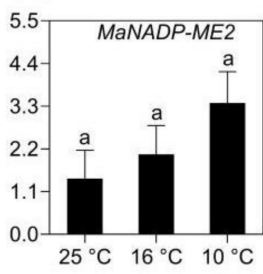

(n)

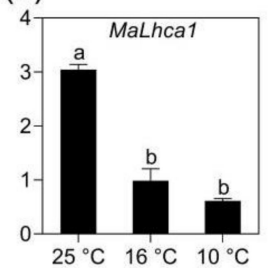

(q)

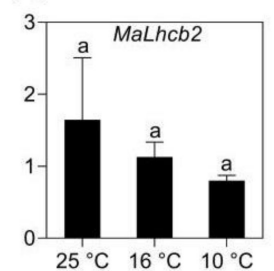

(t)

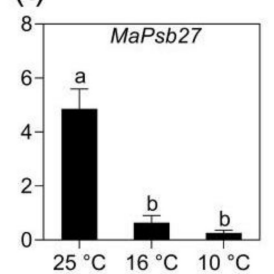

(c)

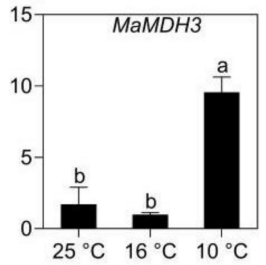

(f)

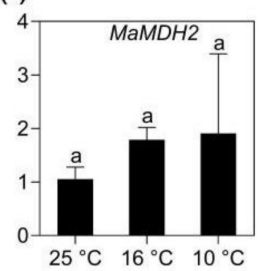

(i)

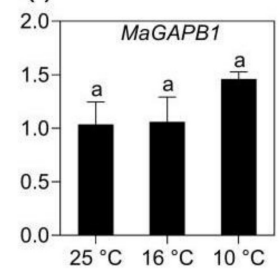

(I)

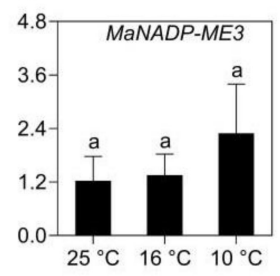

(o)

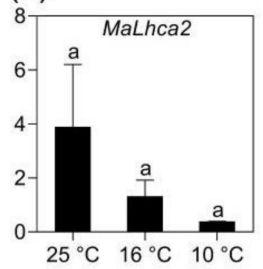

(r)

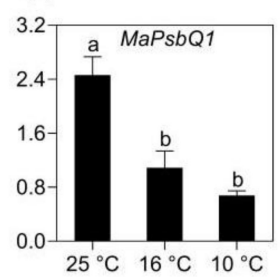

(u)

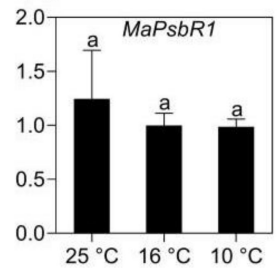

Figure 8. qPCR analysis of the expression of photosynthesis-related genes in banana (Musa spp. AAA) exposed to low temperatures. (a-b) Phosphoglycerate kinase genes; (c-f) Malate dehydrogenase genes; 
(g-i) Glyceraldehyde-3-phosphate dehydrogenase genes; (j-1) NADP-dependent malic enzyme genes; $(\mathbf{m}-\mathbf{q})$ Light-harvesting chlorophyll protein complex genes; $(\mathbf{r}-\mathbf{u})$ Photosystem I and 11 reaction center protein genes. Data represent an average of three replicates \pm standard error. Different letters above the columns represent significant difference using Duncan's multiple range test at $p<0.05$ after angular transformation of the data.

\subsection{Immunofluorescence Labeling of Photosynthetic Proteins in Banana during Chilling Stress}

To confirm the LT-induced changes of some genes/proteins involved in photosynthesis and carbon fixation, we employed immunofluorescence labeling using three antibodies specifically recognizing the key enzymes involved in carbon fixation and two proteins of photosystems. Antibodies recognizing the PSI type I chlorophyll a/b-binding protein (AS1005) and the $23 \mathrm{kDa}$ protein of the oxygen evolving complex of PSII (PsbP) (assigned as AS06142.23) showed a strong signal in the mesophyll and guard cells, as shown in Figure 9a,b. Immunolabeling using antibodies recognizing the Rubisco small subunit (assigned as AS07259) and PEPC (assigned as AS09458) were also localized in the mesophyll and guard cells, but showed much weaker signals when compared to AS1005 and AS06142.23, especially in the mesophyll cells, as shown in Figure 9c,d. The Rubisco large subunit (immunolabeled with antibody assigned as AS03037) appeared in all cross sections through the banana leaves, providing a strong signal in the "Kranz" leaf vein and mesophyll cells, as shown in Figure 9e. As shown in Figure 6f, when the temperature dropped to $16^{\circ} \mathrm{C}$ and $10{ }^{\circ} \mathrm{C}$, the antigens of AS1005 and AS07259 were significantly upregulated. When the temperature further dropped to $10^{\circ} \mathrm{C}$, the expression levels of the Rubisco large subunit and PEPC were also significantly higher than those in CK. No significant changes were observed for the oxygen evolving complex, as shown in Figure $9 \mathrm{f}$.
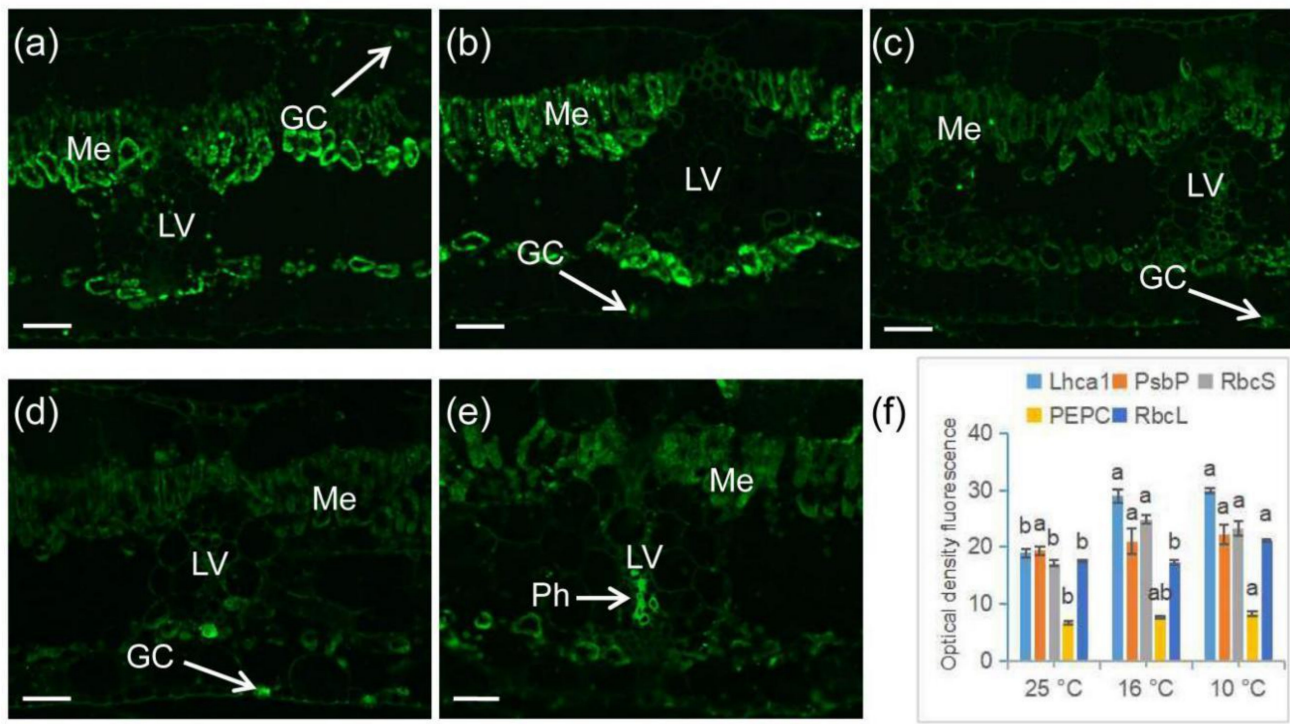

Figure 9. Distribution and localization of proteins involved in photosynthesis and changes in their levels in banana (Musa spp. AAA) in response to chilling stress. (a) AS01005 antibody recognizing PSI type I chlorophyll a/b-binding protein (Lhca1); (b) AS06142-23 antibody recognizing the oxygen evolving complex of PSII (PsbP); (c) AS07259 antibody recognizing the Rubisco small subunit (RbcS); (d) AS09458 antibody recognizing phosphoenolpyruvate carboxylase (PEPC); (e) AS03037 antibody recognizing the Rubisco large subunit (RbcL); (f) quantification of fluorescence signal. Data are the average of three replicates \pm standard error. Different letters above the columns represent significant difference using Duncan's multiple range test at $p<0.05$ after angular transformation of the data (the statistical analysis was carried out for the differences among three temperature points for each antibody separately). GC; guard cells, LV; leaf vein, Me; mesophyll, Ph; phloem. Bars represent $50 \mu \mathrm{m}$. 


\section{Discussion}

\subsection{Mild and Moderate Chilling Results in Substantial Changes of Gene/Protein Expression in Banana}

Mild and moderate chilling stresses are frequently encountered by banana and other tropical crops. However, nearly all previous studies on banana chilling tolerance were only related to $\mathrm{LT} \leq 10^{\circ} \mathrm{C}[3,10,18]$.

Omics technologies have brought about a significant breakthrough in the knowledge about plant responses to LTs [3-7]. In the present study, global differences in mRNAs caused by mild and moderate chilling were systematically identified and analyzed in China's most important banana cultivar with an annual yield of several million tons. The results showed that this banana cultivar responded to LT16 more dramatically, and differently, compared to LT10. In total, 1933 DEGs were identified in banana leaves after exposure to $16{ }^{\circ} \mathrm{C}$ with comparison to 1267 ones at $10{ }^{\circ} \mathrm{C}$, while it was 279 for LT10-LT16. The most significantly differentially expressed KEGG pathways between these two LT points were related to plant hormone signal transduction, ABC transporters, ubiquinone, and other terpenoid-quinone biosynthesis. On the other hand, many annotations were overabundant between LT16 and LT10. Upon stress of LT $\geq 10^{\circ} \mathrm{C}$, this CS banana cultivar accelerated carbon fixation, carbon metabolism, upregulated biosynthesis of flavonoid, cutin, suberine, and wax, but downregulated photosynthetic proteins related to antenna complex.

Similarly, a wild banana, which is extremely cold resistant and resists temperatures close to $0{ }^{\circ} \mathrm{C}[19]$, was used to profile the cold-responsive mRNAs and lncRNAs by RNA-seq at different LT points $\left(13,4\right.$, and $\left.0{ }^{\circ} \mathrm{C}\right)$ [20]. In total, 1530 transcripts were found to be differentially expressed at $13^{\circ} \mathrm{C}$, and the most enriched 20 KEGG pathways also included photosynthesis-antenna proteins and carbon fixation. However, whether these pathways were up or downregulated is not mentioned. In CS maize (Zea mays), however, few photosynthesis-related genes were repressed by chilling, though hundreds of transcripts were affected by LT of $14{ }^{\circ} \mathrm{C}$ [11]. In contrast, Miscanthus $\times$ giganteus, an exceptional CT $\mathrm{C}_{4}$ species closely related to maize, could keep its ability to acclimate to a chilling condition $\left(\leq 14^{\circ} \mathrm{C}\right)$ and maintain relatively high photosynthetic capacity. This was reflected also in transcript profiles of photosynthetic proteins, because genes associated with photosynthetic light reactions were upregulated, while they were reduced in CS maize after 14 days of treatment at $14{ }^{\circ} \mathrm{C}$ [12]. Thus, the response of tropical banana to $\mathrm{LT} \geq 10^{\circ} \mathrm{C}$ showed partial similarity to CS crop maize, suggesting that the responses of tropical plants to $\mathrm{LT} \geq 10^{\circ} \mathrm{C}$ exhibit certain specificities.

\subsection{Upregulation of Carbon Fixation and Downregulation of the Electron Transport Chain in the Banana Response to Mild and Moderate Chilling Stresses}

Photosynthesis is the most fundamental and intricate physiological process in all green plants. Abiotic stresses, including LT, seriously affect plant photosynthesis through disruption of the components of photosynthesis system, including chlorophyll photosystem I and II, electron transport, as well as carbon fixation, and stomatal conductance [22]. Many previous studies have demonstrated that LT stress inhibits photosynthesis, as indicated by reduction in the net photosynthetic rate, stomatal conductance, and maximum photochemical efficiency (Fv/Fm) [10,23,24].

To survive in a fluctuating environment, plants develop some mechanisms to adapt to the new conditions, such as adjustment of cell wall metabolism and adaptation to photosynthetic machinery [25]. In this study, both RNA-seq and proteomics results indicated that light reactions were downregulated in banana upon mild chilling stress. However, mild to moderated LTs upregulated carbon fixation and did not affect the intercellular $\mathrm{CO}_{2}$ concentration, though the stomatal conductance was significantly decreased. Such conditions supported the elevated carboxylation reactions (Rubisco, PEPC, and PPDK) as found by biochemical, proteomic, transcriptomic, and immunolabeling analyses. An increase in protein levels of the Rubisco large subunit was also observed in a CT banana genotype (Musa spp. ABB) after exposure to $10^{\circ} \mathrm{C}[10]$ and a CS banana genotype (Musa spp. AAA) after exposure to $5{ }^{\circ} \mathrm{C}[18]$. These results suggested that banana maintained the intracellular $\mathrm{CO}_{2}$ concentration 
through upregulation of PEPCs and PPDKs, which catalyze the regeneration of PEP under mild and moderate chilling stresses. Such increased PEPC levels might enhance the carbon assimilation rate and thereafter support the acclimation to LT in order to maintain the net photosynthetic rate upon LT $\geq 10{ }^{\circ} \mathrm{C}$, although many genes related to PSII and photosynthesis-antenna proteins were downregulated. Similar to our results, the protein levels of Rubisco activase and the expression of genes of the Benson-Calvin cycle simultaneously increased also in CS watermelon (Citrullus lanatus (Thunb.) Matsum and Nakai) in response to LT [26]. Naidu et al. [27] revealed that photosynthesis, PPDK, and the Rubisco large subunit decreased by $80 \%, 50 \%$, and 30\%, respectively, in CS maize during LT, whereas these levels remained unaffected in its close $\mathrm{C}_{4}$ plant, the CT Miscanthus $\times$ giganteus. The authors suggested that the maintenance of PPDK and Rubisco large subunit expression in $M$. giganteus were critical for high rates of $\mathrm{C}_{4}$ photosynthesis at LT. Similar results were obtained by more recent observations for maize, $M . \times$ giganteus, and related species during LT stress [11,12,23,28-31]. These results suggested that CT M. $\times$ giganteus under chilling stress maintains Asat and photosynthesis through keeping stable or even increasing levels and activities of PPDK and Rubisco, as well as genes/enzymes associated with chloroplast membrane function. On the other hand, LTs resulted in a significant decrease of Asat and photosynthesis in CS maize through the loss of efficiency of PSII, which is associated with impairment in the synthesis of key PSII and light-harvesting complex proteins [32]. Differently, it has been proven that the activity and activation of PEPC and Rubisco were not significantly affected by chilling in Paspalum dilatatum [33], and the chilling-dependent inhibition of photosynthesis was not related to the maximal phosphoenolpyruvate carboxylation rate [34]. In the present study, no significant change in SPAD was observed in chilling treated banana, but it was not the case for rice as a model $C_{3}$ plant [35]. These results suggest that the photosynthetic system of plants reacts to the stress differently, according to the plant type, photosynthetic system $\left(C_{3}\right.$ or $\left.C_{4}\right)$, type of stress, time and duration of the stress occurrence, and several other factors [25].

\section{Materials and Methods}

\subsection{Plant Materials and LT Treatment}

A CS banana cultivar "Baxijiao" (Musa AAA, with annual production of several million tons) was used as the plant material. Plant preparation and LT treatment were carried out as described by Yan et al. [36]. The samples for proteomic analysis were collected 2 days after being treated at $25^{\circ} \mathrm{C}$ and $10{ }^{\circ} \mathrm{C}$ for two days, respectively, while it was 25,16 , and $10{ }^{\circ} \mathrm{C}$ for all the other analyses.

\subsection{Measurement of Physiological Parameters}

All physiological analyses were performed on laminas of the second fully developed leaf in three biological replicates. One plant was analyzed within each biological replicate.

The electric conductivity was tested according to the method described by Meng et al. [37].

Relative chlorophyll content was measured nondestructively with a SPAD (Minolta, Osaka, Japan) 502 Chl Meter.

The intercellular $\mathrm{CO}_{2}$ concentration $(\mathrm{Ci})$, the stomatal conductance, and the net photosynthetic rate were measured under standardized conditions with a portable photosynthesis system (PP system TPS-2, Amesbury, MA, USA). The measurement conditions were: $70 \%$ relative air humidity and $420 \mu \mathrm{mol} \mathrm{mol}^{-1}$ ambient $\mathrm{CO}_{2}$ concentration. Three plants were taken as a replicate from each treatment.

\subsubsection{Chlorophyll Fluorescence Imaging}

Stress tolerance was measured based on changes in the maximal photochemical efficiency (Fv/Fm) after LT treatment. Fv/Fm was determined with imaging PAM (IMAG-MAXI; Heinz Walz, Effeltrich, Germany) after the plants were dark adapted for $30 \mathrm{~min}$. Fv/Fm was determined in the whole leaf [38]. 


\subsubsection{Determination of Enzyme Activities of PEPC and Rubisco}

The activity of PEPC and Rubisco was measured as described by Wang et al. [39].

For the determination of PEPC, leaf tissue (about $0.2 \mathrm{~g}$ ) was homogenized in $1.5 \mathrm{~mL}$ extraction buffer containing $0.1 \mathrm{M}$ Tris- $\mathrm{H}_{2} \mathrm{SO}_{4}$ ( $\mathrm{pH} 8.2$ ), $1 \mathrm{mM}$ ethylenediaminetetraacetic acid, $7 \mathrm{mM}$ 2-mercapoethanol, $5 \%(v / v)$ glycerol, and $3 \%(w / v)$ insoluble polyvinylpolypyrrolidone. The homogenate was centrifuged at $16,000 \times \mathrm{g}$ at $4{ }^{\circ} \mathrm{C}$ for $10 \mathrm{~min}$. Following addition of $0.243 \mathrm{~g}$ ammonium sulfate to $1.0 \mathrm{~mL}$ supernatant, it was kept at $4{ }^{\circ} \mathrm{C}$ for $2 \mathrm{~h}$. Afterwards, the mixture was centrifuged at $16,000 \times g$ for $15 \mathrm{~min}$. The precipitate was resuspended in $0.2 \mathrm{~mL}$ extraction buffer. PEPC activity was measured spectrophotometrically by following the reduction of nicotinamide adenine dinucleotide (NADH) at $340 \mathrm{~nm}$ in $1 \mathrm{~mL}$ of mixture containing $50 \mathrm{mM}$ Tris- $\mathrm{HCl}$ ( $\mathrm{pH}$ 9.2), $4 \mathrm{mM}$ phosphoenolpyruvate, $10 \mathrm{mM}$ $\mathrm{Mg}_{2} \mathrm{SO}_{4}, 10 \mathrm{mM} \mathrm{NaHCO}, 0.1 \mathrm{mg} \mathrm{NADH}$, and $5 \mathrm{U}$ malate dehydrogenase. The enzyme activity was calculated from the absorbance value.

For the determination of Rubisco, in brief, frozen leaf discs (about $0.2 \mathrm{~g}$ ) were ground with a pre-cooled mortar and pestle in $1.5 \mathrm{~mL}$ extraction buffer containing $50 \mathrm{mM}$ Hepes- $\mathrm{KOH}(\mathrm{pH} 7.5), 10 \mathrm{mM}$ $\mathrm{MgCl}_{2}, 2 \mathrm{mM}$ ethylenediaminetetraacetic acid, $10 \mathrm{mM}$ dithiothreitol, $1 \%(v / v)$ Triton X-100, 5\% (w/v) insoluble polyvinylpolypyrrolidone, $1 \%(w / v)$ bovine serum albumin, and $10 \%(v / v)$ glycerol. The extract was centrifuged at 13,000 $\mathrm{g}$ for $5 \mathrm{~min}$ in an Eppendorf microcentrifuge, and the supernatant was used immediately for an enzyme activity assay. Rubisco activity was determined at $340 \mathrm{~nm}$ in a mixture $(1 \mathrm{~mL})$ of $100 \mathrm{mM}$ bicine $\mathrm{pH} 8.0,25 \mathrm{mM} \mathrm{KHCO}_{3}, 20 \mathrm{mM} \mathrm{MgCl}_{2}, 3.5 \mathrm{mM}$ ATP, $5 \mathrm{mM}$ phosphocreatine, 5 units glyceraldehyde-3-phosphate dehydrogenase, 5 units 3-phosphoglyceric phosphokinase, 17.5 units creatine phosphokinase, $0.25 \mathrm{mM} \mathrm{NADH}$, and $0.5 \mathrm{mM}$ ribulose-1,5-bisphosphate. Sample $(20 \mu \mathrm{L})$ and ribulose-1,5-bisphosphate were added prior to measurement followed by thorough mixing. The absorbance was monitored at $340 \mathrm{~nm}$.

\subsection{Immuno-labeling of Antibodies Related to Photosynthesis}

Fixation and embedding of samples were carried out according to Xu et al. [40] with the following modifications-an additional step was added between the rinse with phosphate-buffered saline (PBS) after dewaxing and blockage in PBS supplemented with $50 \mathrm{mM}$ glycine. The sections were incubated in $0.1 \mathrm{M}$ citrate buffer ( $\mathrm{pH} 6.0$ ) at $100{ }^{\circ} \mathrm{C}$ for $15 \mathrm{~min}$ for retrieval of the antigens. The primary antibodies included anti-RbcL (Rubisco large subunit; AS03037), anti-RbcS (Rubisco small subunit; AS07259), anti-Lhca1 (PSI type I chlorophyll a/b-binding protein; AS01005), anti-PsbP (23 kDa protein of the oxygen evolving complex of PSII; AS06142), and anti-PEPC (PEPC; AS09458), diluted in PBS containing $1 \%(w / v)$ bovine serum albumin to a final concentration of $0.5 \mu \mathrm{g} / 100 \mu \mathrm{L}$. The secondary antibody was goat anti-rabbit IgG (H\&L) (AS09634). All of these antibodies were from Agrisera (Vännäs, Sweden). Sections probed only with the secondary antibodies were used as negative controls. Three biological replicates were prepared for each treatment. An Axio Imager D2 (ZEISS, Oberkochen, Germany) used to examine the fluorescence.

\subsection{DGE Analysis}

RNA preparation, library preparation for DGE sequencing, and data analysis were carried out as described previously [41]. FDR was used to determine the threshold of the $p$ value in multiple tests and analyses. In the present study, $\mid \log 2$ (fold change) $\mid>1$ and a threshold of FDR values $<0.05$ were used as the threshold to evaluate the significance of DEGs.

\subsection{Proteomic Analysis}

\subsubsection{Sample Preparation and Protein Digestion}

The samples were ground in liquid nitrogen and extracted in lysis buffer ( $8 \mathrm{M}$ urea, $2 \%$ SDS, $1 \times$ protease inhibitor cocktail). Then, the samples were sonicated on ice and centrifuged at 13,000 rpm for $10 \mathrm{~min}$ at $4{ }^{\circ} \mathrm{C}$. The supernatant was precipitated with chilled acetone at $-20{ }^{\circ} \mathrm{C}$ overnight, 
followed by three times of washing with 50\% ethanol and 50\% acetone. The protein concentration was determined with the BCA protein assay and $100 \mu \mathrm{g}$ of total protein was redissolved in $200 \mu \mathrm{L} 8 \mathrm{M}$ urea in $0.1 \mathrm{M}$ Tris/ $\mathrm{HCl}$ ( $\mathrm{pH}$ 8.5). Digestion of proteins was performed using the filter aided sample preparation method and was then performed as previously described [42].

\subsubsection{Tandem Mass Tags Labeling and High-pH Reversed Phase Separation}

The released peptides were collected, lyophilized by SpeedVac, and then labeled with TMT 6-plex reagent according to the manufacturer's instructions. All of the labeled samples were pooled and dried by vacuum centrifugation, followed by separation with high-pH RP chromatography. In detail, the mixed peptide sample was redissolved in buffer A (20 mM ammonium formate in water, $\mathrm{pH} 10.0)$ and gradient-eluted in buffer $\mathrm{B}(20 \mathrm{mM}$ ammonium formate in $80 \% \mathrm{ACN}, \mathrm{pH} 10.0)$ from $5 \%$ to $45 \%$ B over $40 \mathrm{~min}$ at a flow rate of $1 \mathrm{~mL} / \mathrm{min}$ in the column (XBridge C18, $4.6 \times 250 \mathrm{~mm}$, $5 \mu \mathrm{m}$, Waters Corporation, Milford, MA, USA) on an Ultimate 3000 system (Thermo Fisher Scientific, Waltham, MA, USA). Twelve fractions were collected and lyophilized by SpeedVac.

\subsubsection{LC-MS/MS Analysis}

The peptides were redissolved in solvent C (C: $0.1 \%$ formic acid in water) and analyzed on an EASY-nLC 1000 system connected to an Orbitrap Fusion Tribrid mass spectrometer (Thermo Fisher Scientific, Waltham, MA, USA). The peptide sample was loaded (trap column (Thermo Fisher Scientific Acclaim PepMap C18, $100 \mu \mathrm{m} \times 2 \mathrm{~cm}$ ), analytical column (Acclaim PepMap C18, $75 \mu \mathrm{m} \times 15 \mathrm{~cm}$ )) and separated with a 120 min gradient from $3 \%$ to $32 \%$ D (D: $0.1 \%$ formic acid in ACN). The mass spectrometer was run under a data dependent acquisition mode and automatically switched between MS and MS/MS mode. The parameters were: (1) MS: scan range $(m / z)=350-1550$; resolution = 120,000; (2) high energy collisional dissociation MS/MS: resolution $=30,000$; isolation window $=1.6$; automatic gain control target $=4 \times 10^{5}$; collision energy $=30$.

\subsubsection{Protein Identification and Quantification}

All MS/MS spectra were searched against the UniProt Musa malaccensis proteome database using Mascot (v2.5.1) with the following parameters: peptide tolerance, 7.0 ppm; MS/MS tolerance, $0.05 \mathrm{Da}$; tryptic digestion; cysteine carbamidomethylation and TMT6plex of lysine and peptide $\mathrm{N}$ terminus as fixed modifications; oxidation on methionine, acetylation on the protein $\mathrm{N}$ terminus, and deamidation of asparagine and glutamine as variable modifications.

Scaffold (v4.7.5, Proteome Software Inc., Portland, OR, USA) was used to validate the MS/MS-based peptide and protein identification and quantification. Peptide identifications were accepted if they could achieve an FDR less than 1\%, while protein identifications were accepted if they contained at least two independent peptides.

Normalization was performed iteratively (across samples and spectra) on intensities as described [43]. Medians were used for averaging. Spectra data were log-transformed, pruned of those matched to multiple proteins and those missing a reference value, and weighted by an adaptive intensity weighting algorithm. Differentially expressed proteins were determined by applying a Mann-Whitney test corrected by Benjamini-Hochberg with significance level $p<0.02060$ and fold change over 1.3 .

\subsubsection{Bioinformatic Analysis}

The bioinformatic analyses (partial least squares discrimination analysis, volcano plot, hierarchical clustering analysis, gene ontology, KEGG, protein-protein interaction) were performed by using an on-line platform called iOmics Cloud (https://iomicscloud.thermofisher.cn/\#!/login). 


\section{6. $q P C R$}

The qPCR analysis was carried out according to the method described in Meng et al. [36]. The primers used are listed in Supplementary Table S9.

\subsection{Statistical Analysis}

Statistical analyses were performed using analysis of variance (ANOVA) by using the statistical program SPSS 19.0 for Windows (SPSS Inc., Chicago, IL, USA). Three replicates were set for each treatment. Data are presented as the mean \pm SE. Multiple differences among means were evaluated using Duncan's multiple range tests at a 5\% probability level.

\section{Conclusions}

Mild to moderate chilling stress represents a frequently encountered environmental stress for tropical crops such as banana. This study provides thorough comparative molecular analyses on the responses of the LT-sensitive tropical banana genotype to mild and moderate chilling stress. We show that molecular responses of CS banana to mild chilling substantially differ from the response to moderate chilling stress, while banana maintained relatively high net photosynthetic efficiency via upregulation of carbon fixation. Our findings show that banana's responses to chilling are temperature dependent, which has to be considered within future breeding programs.

Supplementary Materials: Supplementary Materials can be found at http:/www.mdpi.com/1422-0067/21/23/ 9326/s1.

Author Contributions: Conceptualization, J.L. and C.X.; Data curation, J.L., T.T., W.Y., Y.T., T.N., Z.H., and C.X.; Formal analysis, J.L., T.T., and C.X.; Funding acquisition, T.T., G.Y., H.C., J.Š., and C.X.; Investigation, J.L.; Methodology, J.L., T.T., J.Š., and C.X.; Project administration, C.X.; Resources, J.L., Y.W., J.M., W.Y., Y.T., T.N., and Z.H.; Supervision, C.X.; Validation, J.L. and C.X.; Visualization, J.L.; Writing-original draft, J.L. and C.X.; Writing-review and editing, J.L., T.T., J.Š., and C.X. All authors have read and agreed to the published version of the manuscript.

Funding: This work was supported by the National Key Research and Development Program of China (2018YFD1000300), the Key Research and Development Program of Guangdong Province for Modern Plant Breeding (2018B020202005), the Guangdong Province Special Fund for Modern Agriculture Industry Technology Innovation Teams (2020KJ109), the Earmarked Fund for Modern Agro-industry Technology Research System (CARS-31-04), and by the European Regional Development Fund (ERDF) for the project "Plants as a tool for sustainable development", No. CZ.02.1.01/0.0/16_019/0000827.

Conflicts of Interest: The authors declare no conflict of interest.

$\begin{array}{ll}\text { Abbreviations } \\ \text { CK } & \text { the control } \\ \text { CS } & \text { chilling-sensitive } \\ \text { CT } & \text { chilling-tolerant } \\ \text { DEG } & \text { differentially expressed gene } \\ \text { DGE } & \text { digital gene expression } \\ \text { FDR } & \text { false discovery rate } \\ \text { kDa } & \text { kilodalton } \\ \text { KEGG } & \text { Kyoto encyclopedia of genes and genomes } \\ \text { LT } & \text { low temperature } \\ \text { LT10 } & \text { LT of } 10^{\circ} \mathrm{C} \\ \text { LT16 } & \text { LT of } 16{ }^{\circ} \mathrm{C} \\ \text { NADH } & \text { nicotinamide adenine dinucleotide } \\ \text { PBS } & \text { phosphate-buffered saline } \\ \text { PEPC } & \text { phosphoenolpyruvate carboxylase } \\ \text { PPDK } & \text { pyruvate, phosphate dikinase } \\ \text { RNA-Seq } & \text { RNA sequencing } \\ \text { SPAD } & \text { Soil Plant Analysis Development }\end{array}$




\section{References}

1. Chinnusamy, V.; Zhu, J.; Zhu, J.K. Cold stress regulation of gene expression in plants. Trends Plant Sci. 2007, 12, 444-451. [CrossRef]

2. Hussain, H.A.; Hussain, S.; Khaliq, A.; Ashraf, U.; Anjum, S.A.; Men, S.N.; Wang, L.C. Chilling and drought stresses in crop plants: Implications, cross talk, and potential management opportunities. Front. Plant Sci. 2018, 9, 393. [CrossRef] [PubMed]

3. Yang, Q.S.; Gao, J.; He, W.D.; Dou, T.X.; Ding, L.J.; Wu, J.H.; Li, C.Y.; Peng, X.X.; Zhang, S.; Yi, G.J. Comparative transcriptomics analysis reveals difference of key gene expression between banana and plantain in response to cold stress. BMC Genom. 2015, 16, 446. [CrossRef] [PubMed]

4. Chen, C.J.; Zhang, Y.F.; Xu, Z.Q.; Luan, A.P.; Mao, Q.; Feng, J.J.; Xie, T.; Gong, X.; Wang, X.S.; Chen, X.; et al. Transcriptome profiling of the pineapple under low temperature to facilitate its breeding for cold tolerance. PLOS ONE 2016, 11, e0163315. [CrossRef] [PubMed]

5. Wang, J.S.; Zhang, Q.; Cui, F.; Hou, L.; Zhao, S.Z.; Xia, H.; Qiu, J.J.; Li, T.T.; Zhang, Y.; Wang, X.J.; et al. Genome-wide analysis of gene expression provides new insights into cold responses in Thellungiella salsuginea. Front. Plant Sci. 2017, 8, 713. [CrossRef] [PubMed]

6. Guo, H.; Wu, T.K.; Li, S.H.; He, Q.; Deng, H.F. The methylation patterns and transcriptional responses to chilling stress at the seedling stage in rice. Int. J. Mol. Sci. 2019, 20, 5089. [CrossRef] [PubMed]

7. Yu, X.L.; Li, Y.H.; He, C.; Zhou, J.T.; Chen, Y.Q.; Yu, Z.; Wang, P.; Ni, D.J. Nonvolatile metabolism in postharvest tea (Camellia sinensis L.) leaves: Effects of different withering treatments on nonvolatile metabolites, gene expression levels, and enzyme activity. Food Chem. 2020, 327, 126992. [CrossRef]

8. Chai, F.M.; Liu, W.W.; Xiang, Y.; Meng, X.B.; Sun, X.M.; Cheng, C.; Liu, G.T.; Duan, L.X.; Xin, H.P.; Li, S.H. Comparative metabolic profiling of Vitis amurensis and Vitis vinifera during cold acclimation. Hortic. Res. 2019, 6, 8. [CrossRef]

9. Zhou, P.L.; Khan, R.; Li, Q.Y.; Liu, G.L.; Xu, N.; Yang, Y.J.; Wang, Y.; Wang, S.S.; Chen, A.G. Transcriptomic analyses of chilling stress responsiveness in leaves of tobacco (Nicotiana tabacum) seedlings. Plant Mol. Biol. Rep. 2019, 38, 1-13. [CrossRef]

10. Yang, Q.S.; Wu, J.H.; Li, C.Y.; Wei, Y.R.; Shen, O.; Hu, C.H.; Kuang, R.B. Quantitative proteomic analysis reveals that antioxidation mechanisms contribute to cold tolerance in plantain (Musa paradisiaca L.; ABB group) seedlings. Mol. Cell. Proteom. 2012, 11, 1853-1869. [CrossRef]

11. Trzcinska-Danielewicz, J.; Bilska, A.; Fronk, J.; Zielenkiewicz, P.; Jarochowska, E.; Roszczyk, M.; Jonczyk, M.; Axentowicz, E.; Skoneczny, M.; Sowinski, P. Global analysis of gene expression in maize leaves treated with low temperature. I. Moderate chilling $\left(14^{\circ} \mathrm{C}\right)$. Plant Sci. 2009, 177, 648-658. [CrossRef]

12. Spence, A.K.; Boddu, J.; Wang, D.; James, B.; Swaminathan, K.; Moose, S.P.; Long, S.P. Transcriptional responses indicate maintenance of photosynthetic proteins as key to the exceptional chilling tolerance of $\mathrm{C}_{4}$ photosynthesis in Miscanthus $\times$ giganteus. J. Exp. Bot. 2014, 65, 3737-3747. [CrossRef] [PubMed]

13. FAOSTAT. 2020. Available online: https://www.fao.org/faostat/en/\#data/QC/visualize (accessed on 15 February 2020).

14. Turner, D.W.; Lahav, E. The growth of banana plants in relation to temperature. Funct. Plant Biol. 1983, 10, 43-53. [CrossRef]

15. Liu, H.; Ouyang, B.; Zhang, J.H.; Wang, T.T.; Li, H.X.; Zhang, Y.Y.; Yu, C.Y.; Ye, Z.B. Differential modulation of photosynthesis, signaling, and transcriptional regulation between tolerant and sensitive tomato genotypes under cold stress. PLoS ONE 2012, 7, e50785. [CrossRef]

16. Xu, C.X. Fruit Cultivation in South China; China Agriculture Press: Beijing, China, 2015; pp. 85-86. ISBN 7-109-07750-0.

17. Xu, C.X.; Chen, J.Z.; Liang, L.F. Effects of low temperature on the contents of glycerol, starch and sugars in banana leaves [in Chinese with English abstract]. J. Fruit Sci. 2000, 17, 105-109.

18. Feng, R.J.; Zhang, L.L.; Wang, J.Y.; Luo, J.M.; Peng, M. Proteomic analysis of cold stress responses in banana leaves. J. Ameri. Soc. Hort. Sci. 2015, 140, 214-222. [CrossRef]

19. Lai, Z.X.; Chen, Y.; Lin, Y.L.; Zhao, Q.Y.; Chen, Y.T. Discovery and taxonomy of wild banana (Musa spp.) in Fuzhou. [in Chinese with an English abstract]. Subtrop. Agric. Res. 2007, 3, 1-5. 
20. Liu, W.H.; Cheng, C.Z.; Lin, Y.L.; Xuhan, X.; Lai, Z.X. Genome-wide identification and characterization of mRNAs and lncRNAs involved in cold stress in the wild banana (Musa itinerans). PLoS ONE 2018, 13, e0200002. [CrossRef]

21. Yamori, W.; Hikosaka, K.; Way, D.A. Temperature response of photosynthesis in $\mathrm{C}_{3}, \mathrm{C}_{4}$, and CAM plants: Temperature acclimation and temperature adaptation. Photosynth. Res. 2014, 119, 101-117. [CrossRef]

22. Sobkowiak, A.; Jończyk, M.; Adamczyk, J.; Szczepanik, J.; Solecka, D.; Kuciara, I.; Hetmańczyk, K.; Trzcinska-Danielewicz, J.; Grzybowski, M.; Skoneczny, M.; et al. Molecular foundations of chilling-tolerance of modern maize. BMC Genom. 2016, 17, 125. [CrossRef]

23. Friesen, P.C.; Sage, R.F. Photosynthetic responses to chilling in a chilling-tolerant and chilling-sensitive Miscanthus hybrid. Plant Cell Environ. 2016, 39, 1420-1431. [CrossRef] [PubMed]

24. Hajihashemi, S.; Noedoost, F.; Geuns, J.M.C.; Djalovic, I.; Siddique, K.H.M. Effect of cold stress on photosynthetic traits, carbohydrates, morphology, and anatomy in nine cultivars of Stevia rebaudiana. Front. Plant Sci. 2018, 9, 1430. [CrossRef] [PubMed]

25. Nouri, M.Z.; Moumeni, A.; Komatsu, S. Abiotic stresses: Insight into gene regulation and protein expression in photosynthetic pathways of plants. Int. J. Mol. Sci. 2015, 16, 20392-20416. [CrossRef] [PubMed]

26. Lu, J.Y.; Nawaz, M.A.; Wei, N.N.; Cheng, F.; Bie, Z.L. Suboptimal temperature acclimation enhances chilling tolerance by improving photosynthetic adaptability and osmoregulation ability in watermelon. Hortic. Plant J. 2020, 6, 49-60. [CrossRef]

27. Naidu, S.L.; Moose, S.P.; AL-Shoaibi, A.K.; Raines, C.A.; Long, S.P. Cold tolerance of $\mathrm{C}_{4}$ photosynthesis in Miscanthus $\times$ giganteus: Adaptation in amounts and sequence of $\mathrm{C}_{4}$ photosynthetic enzymes. Plant Physiol. 2003, 132, 1688-1697. [CrossRef]

28. Wang, D.F.; Naidu, S.L.; Portis, A.R., Jr.; Moose, S.P.; Long, S.P. Can the cold tolerance of $C_{4}$ photosynthesis in Miscanthus $\times$ giganteus relative to Zea mays be explained by differences in activities and thermal properties of Rubisco? J. Exp. Bot. 2008, 59, 1779-1787. [CrossRef]

29. Wang, D.F.; Portis, A.R.; Moose, S.P.; Long, S.P. Cool $C_{4}$ photosynthesis: Pyruvate $P_{i}$ dikinase expression and activity corresponds to the exceptional cold tolerance of carbon assimilation in Miscanthus $\times$ giganteus. Plant Physiol. 2008, 148, 557-567. [CrossRef]

30. Long, S.P.; Spence, A.K. Toward cool C 4 crops. Annu. Rev. Plant Biol. 2013, 64, 701-722. [CrossRef]

31. Bilska-Kos, A.; Panek, P.; Szulc-Głaz, A.; Ochodzki, P.; Cisło, A.; Zebrowski, J. Chilling-induced physiological, anatomical and biochemical responses in the leaves of Miscanthus $\times$ giganteus and maize (Zea mays L.). J. Plant Physiol. 2018, 228, 178-188. [CrossRef]

32. Caffarri, S.; Frigerio, S.; Olivieri, E.; Righetti, P.G.; Bassi, R. Differential accumulation of Lhcb gene products in thylakoid membranes of Zea mays plants grown under contrasting light and temperature conditions. Proteomics 2005, 5, 758-768. [CrossRef]

33. Cavaco, A.M.; De Silva, A.B.; Arrabaca, M.C. Effects of long-term chilling on growth and photosynthesis of the $\mathrm{C}_{4}$ gramineae Paspalum dilatatum. Physiol. Plant. 2003, 119, 87-96. [CrossRef]

34. Soares-Cordeiro, A.S.; Driscoll, S.P.; Arrabaca, M.C.; Foyer, C.H. Dorsoventral variations in dark chilling effects on photosynthesis and stomatal function in Paspalum dilatatum leaves. J. Exp. Bot. 2010, 62, 687-699. [CrossRef] [PubMed]

35. Sharma, P.; Sharma, N.; Deswal, R. The molecular biology of the low-temperature response in plants. Bioessays 2005, 27, 1048-1059. [CrossRef] [PubMed]

36. Yan, Y.L.; Takác, T.; Li, X.Q.; Chen, H.B.; Wang, Y.Y.; Xu, E.F.; Xie, L.; Su, Z.H.; Šamaj, J.; Xu, C.X. Variable content and distribution of arabinogalactan proteins in banana (Musa spp.) under low temperature stress. Front. Plant Sci. 2015, 6, 353. [CrossRef]

37. Meng, J.; Hu, B.; Yi, G.J.; Li, X.Q.; Chen, H.B.; Wang, Y.Y.; Yuan, W.N.; Xing, Y.Q.; Sheng, Q.M.; Su, Z.X.; et al. Genome-wide analyses of banana fasciclin-like AGP genes and their differential expression under low-temperature stress in chilling sensitive and tolerant cultivars. Plant Cell Rep. 2020, 39, 693-708. [CrossRef]

38. Xia, X.J.; Wang, Y.J.; Zhou, Y.H.; Tao, Y.; Mao, W.H.; Shi, K.; Asami, T.; Chen, Z.X.; Yu, J.Q. Reactive oxygen species are involved in brassinosteroid-induced stress tolerance in cucumber. Plant Physiol. 2009, 150, 801-814. [CrossRef]

39. Wang, L.; Zhang, X.; Ma, Y.H.; Qing, Y.H.; Wang, H.C.; Huang, X.M. The highly drought-tolerant pitaya (Hylocereus undatus) is a non-facultative CAM plant under both well-watered and drought conditions. J. Horticult. Sci. Biotechnol. 2019, 94, 643-652. [CrossRef] 
40. Xu, C.X.; Takáč, T.; Burbach, C.; Menzel, D.; Samaj, J. Developmental localization and the role of hydroxyproline rich glycoproteins during somatic embryogenesis of banana (Musa spp. AAA). BMC Plant Biol. 2011, 11, 38. [CrossRef]

41. Niu, Y.Q.; Hu, B.; Li, X.Q.; Chen, H.B.; Takáč, T.; Šamaj, J.; Xu, C.X. Comparative digital gene expression analysis of tissue-cultured plantlets of highly resistant and susceptible banana cultivars in response to Fusarium oxysporum. Int. J. Mol. Sci. 2018, 19, 350. [CrossRef]

42. Fang, D.L.; Yang, W.J.; Deng, Z.L.; An, X.X.; Zhao, L.Y.; Hu, Q.H. Proteomic investigation of metabolic changes of mushroom (Flammulina velutipes) packaged with nanocomposite material during cold storage. J. Agric. Food Chem. 2017, 65, 10368-10381. [CrossRef]

43. Oberg, A.L.; Mahoney, D.W.; Eckel-Passow, J.E.; Malone, C.J.; Wolfinger, R.D.; Hill, E.G.; Cooper, L.T.; Onuma, O.K.; Spiro, C.; Therneau, T.M.; et al. Statistical analysis of relative labeled mass spectrometry data from complex samples using ANOVA. J. Proteome Res. 2008, 7, 225-233. [CrossRef] [PubMed]

Publisher's Note: MDPI stays neutral with regard to jurisdictional claims in published maps and institutional affiliations.

(C) 2020 by the authors. Licensee MDPI, Basel, Switzerland. This article is an open access article distributed under the terms and conditions of the Creative Commons Attribution (CC BY) license (http://creativecommons.org/licenses/by/4.0/). 